\title{
Forearm Venous Distensibility in Relation to Severity of Symptoms and Hemodynamic Data in Patients with Congestive Heart Failure
}

\author{
Hiroshi Ikenouchi, M.D., Masahiko Imzuka, M.D., \\ Hiroshi Sato, M.D., Shin-ichi Momomura, M.D., \\ Takashi Serizawa, M.D., and Tsuneaki Sugimoto, M.D.
}

\section{SUMMARY}

The distensibility of the forearm veins in 24 paticnts with congestive heart failure was studied by occlusion plethysmography. Relationships between forearm venous distensibility and symptoms, hemodynamic data obtained by right heart catheterization and plasma levels of vasoactive hormones were evaluated. Forearm venous pressure (VP) and volume change $(\Delta \mathrm{V})$ were measured simultaneously by the venous occlusion technique with strain gauge plethysmography. The relationship between venous pressure and volume change was fitted by the equation $\mathrm{VP}=$ $\mathrm{c}^{*} \exp .(\mathrm{k} * J \mathrm{~V})(\mathrm{r}=0.98 \pm 0.01)$ and the venous stiffness constant $(\mathrm{k})$ was calculated. Venous volume change at a venous pressure of $20 \mathrm{mmHg}$ (V20) was also measured as another index of venous compliance. The pressure-volume curve of the peripheral veins shifted leftward on the volume axis and the stiffness constant $(\mathrm{k})$ increased as the New York Heart Association functional class grade increased. Mean pulmonary arterial pressure and pulmonary vascular resistance were closely related to $\mathrm{k}$ $(\mathrm{r}=0.74, \mathrm{p}<0.001 ; \mathrm{r}=0.73, \mathrm{p}<0.001$, respectively), and less closely to $\mathrm{V} 20(\mathrm{r}=-0.56, \mathrm{p}<0.004 ; \mathrm{r}=-0.59, \mathrm{p}<0.002$, respectively). $\mathrm{K}$ and V20 were also related to stroke index $(r=-0.57, p<0.004 ; r=0.44, p<0.03$, respectively) and stroke work index $(r=-0.47, p<0.02 ; \mathrm{r}=0.45, \mathrm{p}<0.03$, respectively). $\mathbf{K}$ was also related to heart rate $(\mathrm{r}=0.55, \mathrm{p}<0.007)$, pulmonary capillary wedge pressure $(\mathrm{r}=0.54, \mathrm{p}<0.02)$, right atrial pressure $(\mathrm{r}=0.51, \mathrm{p}<0.02)$, cardiac index $(\mathrm{r}=-0.45, \mathrm{p}<0.03)$, and systemic vascular resistance $(r=0.45, p<0.03)$. Both indexes were related to the plasma level of norepinephrine $(\mathrm{r}=0.64, \mathrm{p}<0.008 ; \mathrm{r}=-0.52, \mathrm{p}<0.04$, respectively). We concluded that the venous tone was related to the severity of heart failure, especially to the symptoms, pulmonary arterial pressure and plasma concentration of norepinephrine, and that the venous stiffness constant, $\mathrm{k}$, was a better parameter with which to assess peripheral venous tone.

From the Second Department of Internal Medicine, Faculty of Medicine, University of Tokyo, Hongo, Bunkyo-ku, Tokyo, Japan.

Address for correspondence: Hiroshi Ikenouchi, M.D., Cardiology Division, University of Utah, Medical Center, 50 North Medical Drive, Salt Lake City, Utah 84132, U.S.A.

Received for publication July 10, 1990.

Accepted July 20, 1990. 


\title{
Additional Indexing Words:
}

Venous tone Strain-gauge plethysmography Peripheral circulation

\begin{abstract}
A
CCORDING to the theory proposed by Guyton, cardiac output and ventricular filling pressure are determined by the combination of the cardiac function curve and venous return curve." Venous distensibility and blood volume are the two main determinants of the venous return curve through mean systemic pressure. In patients with congestive heart failure, the presence of generalized arteriolar and venous constriction is well known. ${ }^{2,3}$ These vasoconstrictions are mediated in part by enhanced sympathetic nervous system activity. In addition, the concentration of angiotensin II is elevated, contributing to both arterial vasoconstriction and the increase in venous tone. ${ }^{4,5)}$ Increased plasma concentrations of vasopressin, prostaglandins and other vasoconstrictor peptides may also contribute to an increase in vascular tone. ${ }^{2)}$ Increased extravascular fluid or edema can also increase the tissue pressure compressing the systemic veins. The effectiveness of preload reduction by venodilatation therapy provides evidence supporting the above ${ }^{6)} \mathrm{Al}$ though decreased venous distensibility has been frequently reported in congestive heart failure, ${ }^{7-12)}$ its detailed relationships to hemodynamic parameters in patients with congestive heart failure have not been elucidated in previous studies.

We studied the characteristics of forearm peripheral circulation by straingauge plethysmography and quantified the distensibility of veins in patients with congestive heart failure, and compared it with clinical severity and hemodynamic data.
\end{abstract}

\section{Methods}

Subjects :

Twenty four patients (18 males and 6 females) with congestive heart failure, mean age $55 \pm 12$ years, admitted to the Hospital of the University of Tokyo, were divided into 4 groups according to the New York Heart Association (NYHA) functional classification ${ }^{13}$ ) (Table I) (Group 1: NYHA I, $n=7$, Group 2: II, $n=7$, Group 3: III, $n=5$, Group 4: IV, $n=5$ ). Informed consent to participate in this study was obtained from each patient and the study protocol was approved by the Ethical Committee of the Hospital of the University of Tokyo (Nov. 1, 1986).

The underlying diseases, duration of congestive heart failure and treatment before admission in each class are listed in Table I. All diuretics and vasodilating drugs were discontinued at least 12 hours prior to the onset of the 
Table 1. Underlying Heart Diseases and Severity of Congestive Heart Failure

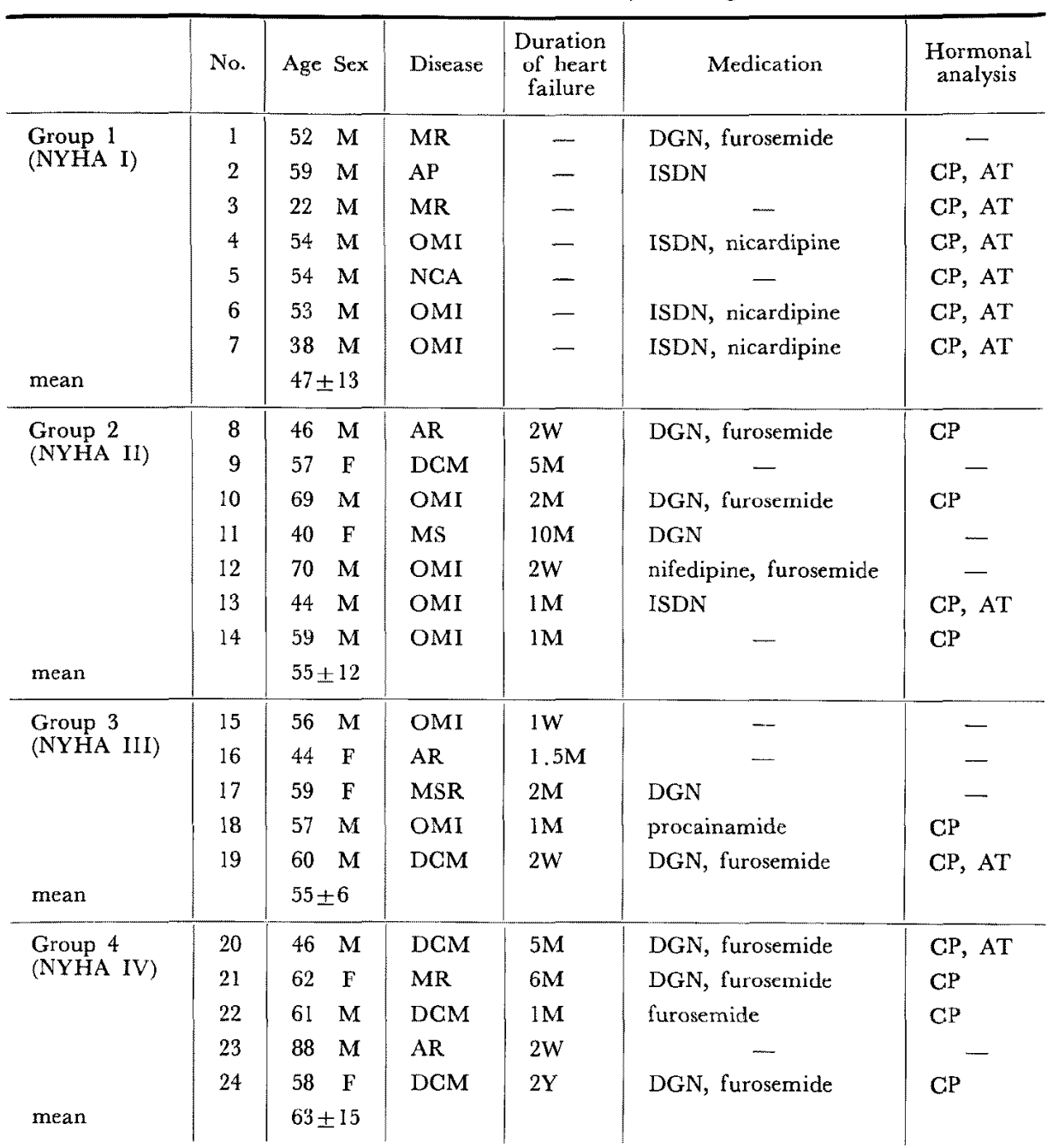

NYHA $=$ New York Heart Association; $\mathrm{MR}=$ mitral regurgitation; $\mathrm{AP}=$ angina pectoris ; $\mathrm{OMI}$ =old myocardial infarction; $\mathrm{NGA}=$ neurocirculatory asthenia, $\mathrm{AR}=$ aortic regurgitation $; \mathrm{DCM}=$ dilated cardiomyopathy; $\mathrm{MS}=$ mitral stenosis ; $\mathrm{DGN}=$ digoxin $; \mathrm{ISDN}=$ isosorbide dinitrate ; $\mathrm{CP}=$ plasma catecholamines concentration analysis; $\mathrm{AT}=$ plasma angiotensin II concentration analysis.

study except in Group 4, where diuretics were continued throughout the study. The difference of mean ages among groups was statistically insignificant. In 16 patients, serum samples were obtained and analyzed to evaluate the concentration of plasma catecholamines and in 9 of the 16 patients the plasma concentration of angiotensin II was also measured.

\section{Hemodynamic measurements:}

The patients were placed in the supine position or head-up supine posi- 
tion and a balloon thermodilution catheter was inserted via an introducer sheath placed into the subclavian or internal jugular vein. Cardiac output by the thermodilution technique, pulmonary capillary wedge pressure, pulmonary arterial pressure and right atrial pressure were measured through the fluid-filled catheter with a pressure transducer (Statham P-50, Gould Inc.). A short venous catheter $(20 \mathrm{G})$ was inserted into a subcutaneous vein of the forearm near the strain gauge for continuous pressure monitoring via another transducer (Statham P-50, Gould Inc.) and kept patent by the infusion of a heparinized saline solution $(10 \mu / \mathrm{ml})$. Heart rate, blood pressure and hemodynamic parameters were measured twice at 15 min intervals, and stability of the hemodynamic status of the patient was verified.

Plethysmographic technique:

Forearm plethysmography ${ }^{14,15)}$ was carried out with the subject relaxed in a supine position or head-up supine position, with the right or left arm supported at a level above the heart in order to empty the vein. A venous occlusion cuff $(8.5 \times 33 \mathrm{~cm})$ was placed around the arm just above the elbow. Another pneumatic cuff was placed around the wrist. A silicone strain gauge (SG-24, Medasonics Inc.), $24 \mathrm{~cm}$ in length, was positioned so that it encircled the forearm at its widest part. Any increase in the volume of the limb stretches the strain gauge. The correlation between the increase in length of the strain gauge and that of the electrical resistance is linear within the extent of changes seen in this study. The wrist cuff was inflated to well above the systolic blood pressure to exclude circulation to the hand. Volume changes were calculated by a computer (SPG 16, Medasonics Inc.) from those of the forearm girth on the assumption that the shape of the cross section of the forearm is constant. These data were monitored and recorded on paper by a monitoring and recording system (Dynascope DS-1100, AO-5001, Fukuda Denshi Inc.) for further analyses. With the recording paper running $(1 \mathrm{~mm} / \mathrm{sec})$, the upper arm cuff was rapidly inflated to $40 \mathrm{mmHg}$ until the venous pressure was elevated to over $24 \mathrm{mmHg}$ or until a plateau was obtained. The upper arm cuff was then deflated and the tracing was allowed to return to baseline before another flow recording was made (Fig. 1). A series of four measurements were used to determine an average value of forearm blood flow and venous compliance. Forearm arterial resistance was calculated from the forearm blood flow and the mean arterial pressure measured in the opposite arm. Forearm venous compliance was assessed from the pressure-volume relation during each inflation. The change in forearm volume was plotted against the change in forearm venous pressure from 2 to $24 \mathrm{mmHg}$ in $2 \mathrm{mmHg}$ steps, i.e., in 12 points. Throughout each study the room temperature was maintained between 23 and 26 degrees centigrade. 

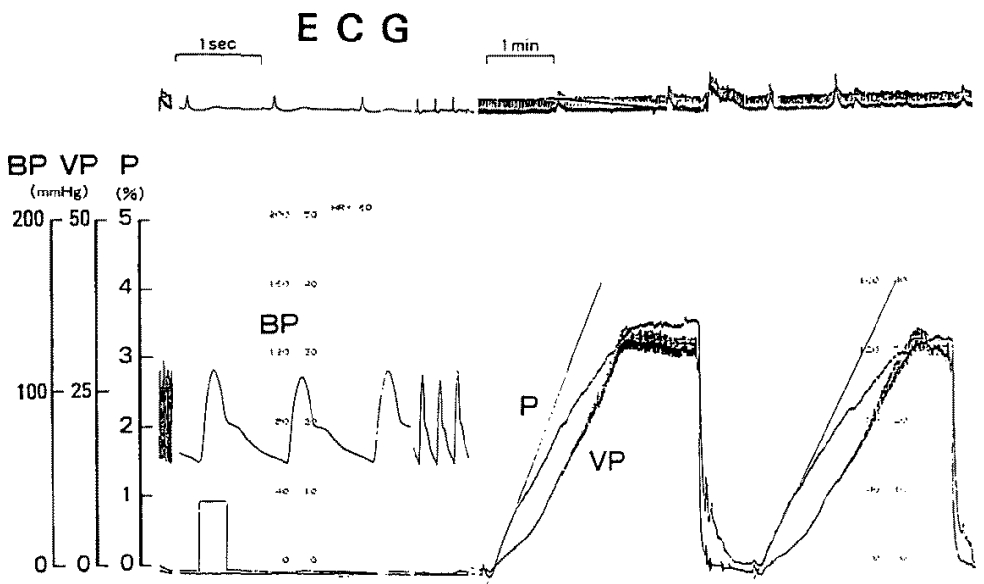

Fig. 1. A recording obtained by the acute occlusion method. The tracing on the left is systemic blood pressure, and those on the right are the responses of venous pressure and volume. Forearm blood flow was calculated from the initial slope of the volume change curve. ECG=electrocardiogram; $\mathrm{BP}=$ blood pressure; $\mathrm{VP}=$ venous pressure; $\mathbf{P}=\%$ change of volume by plethysmography.

Heart rate was automatically measured and recorded on the paper and blood pressure was measured by a conventional sphygmomanometer or was monitored continuously with a cannula inserted into a forearm artery via a transducer.

Calculation of venous stiffness constant:

In previous reports human forearm venous distensibility evaluated by plethysmography has been discussed with forearm venous pressure volume curves or a venous volume at a venous pressure $(30 \mathrm{mmHg})$ as a measure of venous compliance. Venous pressure volume curves are good ways to visualize the venous distensibility but it is difficult to quantify it. Venous compliance at one point of venous pressure may not reflect the entire venous pressure-volume relationship. The venous stiffness constant $(\mathrm{k})$ was calculated from the forearm pressure-volume curve by fitting it to an exponential equation using 12 points $(2-24 \mathrm{mmHg})(\mathrm{r}=0.98 \pm 0.01)$;

$$
V P=a^{*} \mathrm{e}^{\mathrm{k} * V}
$$

where $\mathrm{VP}$ is venous pressure, $\mathrm{V}$ is the change in forearm volume and a is a constant. Actually, our plethysmography technique measures only changes of venous pressure $(\Delta \mathrm{P})$ and forearm volume $(\Delta \mathrm{V})$. Absolute venous pressure $(\mathrm{VP})$ and forearm volume $(\mathrm{V})$ are expressed as follows; $\mathrm{VP}=\mathrm{Po}+\Delta \mathrm{P}, \mathrm{V}=$ $\mathrm{Vo}+\Delta \mathrm{V}$ : where $\mathrm{Po}$ is the initial venous pressure and $\mathrm{Vo}_{\mathrm{o}}$ is the initial absolute 
forearm volume.

$$
(\mathrm{Po}+\Delta \mathrm{P})=\mathrm{a}^{*} \mathrm{e}^{\mathrm{k}^{*}\left(\mathrm{~V}_{\mathrm{o}}+\Delta \mathrm{V}\right)}
$$

Po was set in this study to zero by arm elevation.

$$
\mathrm{P}=\mathrm{a}^{*} \mathrm{e}^{\mathrm{k} * \mathrm{~V}} \mathrm{v}_{\mathrm{a}} \mathrm{e}^{\mathrm{k}^{*} \Delta \mathrm{V}}=\mathrm{c}^{*} \mathrm{c}^{\mathrm{k} \Delta \mathrm{V}}
$$

From these relations, the venous stiffness constant, $k$, does not include initial absolute forearm volume. In the above equation $\mathrm{c}$ is the other constant and could reflect the distensibility of forearm veins. In this study, the change in this constant was in the same direction and the change was much smaller than that of $k$, so we used $k$ as an index of venous distensibility.

The amount of venous volume change at a venous pressure of $20 \mathrm{mmHg}$, "V20" was also measured as the venous compliance at a single pressure point.

\section{Hormonal analysis:}

After more than $30 \mathrm{~min}$ of bed rest in the supine or head-up supine position at the start of the study, blood samples were taken and immediately cooled to below 0 degrees centigrade. Then these were centrifuged under low temperature ( 0 degrees centigrade) as soon as the procedure was finished. The plasma samples were analyzed to determine hormonal concentrations. Epinephrine and norepinephrine were analyzed by a radioimmunoassay technique, in which the normal concentrations were $<120 \mathrm{pg} / \mathrm{ml}$ and $40-350 \mathrm{pg} /$ $\mathrm{ml}$, respectively. Angiotensin II was analyzed by the high performance liquid chromatography method with which the normal range was $<60 \mathrm{pg} / \mathrm{ml}$.

\section{Calculation:}

Systemic vascular resistance (SVR) was calculated by the equation $(\mathrm{mBP}-\mathrm{RAP}) * 80 / \mathrm{CO}\left(\right.$ dyne $\left.{ }^{*} \mathrm{sec} / \mathrm{cm}^{5}\right)$, where $\mathrm{mBP}$ : mean blood pressure $(\mathrm{mmHg}), \mathrm{RAP}$ : right atrial pressure $(\mathrm{mmHg}), \mathrm{CO}:$ cardiac output $(1 / \mathrm{min})$. Pulmonary vascular resistance (PVR) was calculated by the equation (mPAP$\mathrm{PCW}) * 80 / \mathrm{CO}\left(\right.$ dyne ${ }^{*} \mathrm{sec} / \mathrm{cm}^{5}$ ), where mPAP: mean pulmonary arterial pressure $(\mathrm{mmHg}), \mathrm{PCW}$ : pulmonary capillary wedge pressure $(\mathrm{mmHg})$. Stroke work (SW) was obtained from the equation $\mathrm{SV}^{*}(\mathrm{mBP}-\mathrm{PCW})(\mathrm{ml} * \mathrm{mmHg} /$ beat). Stroke work index (SWI) was calculated from the equation SI*mBP $\left(\mathrm{ml}^{*} \mathrm{mmHg} / \mathrm{m}^{2} /\right.$ beat $)$.

Forearm blood flow (FBF; $\mathrm{ml} / 100 \mathrm{ml}$, tissue $/ \mathrm{min}$ ) was determined from the initial slope of the volume change curve (Fig. l). Forearm vascular resistance was calculated using the formula $\mathrm{FBF}(\mathrm{ml} / 100 \mathrm{ml}$, tissue $/ \mathrm{min}) / \mathrm{mBP}$ $(\mathrm{mmHg})$.

Statistical analysis:

All values are presented as means $\pm \mathrm{SD}$. Differences among all NYHA 
groups were analyzed by one-way analysis of variance followed by a comparison with unpaired modified Student's t-test. P values less than 0.05 were considered to be significant. Relations between $\mathrm{k}$ and other parameters were evaluated by linear regression analysis and considered as significant if $\mathrm{p}<0.05$.

\section{Results}

\section{NYHA functional class and hemodynamic parameters:}

Hemodynamic parameters determined by right heart catheterization and simultaneous plethysmographic study are shown in Table II. Hemodynamic data were significantly different among groups of patients with congestive

Table II. Relation between Severity of Congestive Heart Failure and Central and Peripheral Hemodynamic Parameters in Each Group

\begin{tabular}{|c|c|c|c|c|c|}
\hline & Group 1 & Group 2 & Group 3 & Group 4 & $\mathrm{n}$ \\
\hline Heart rate (beat/min) & $66 \pm 10$ & $81 \pm 15$ & $92 \pm 28$ & $94 \pm 23$ & ns \\
\hline $\begin{array}{l}\text { Mean blood pressure } \\
\text { (mmHg) }\end{array}$ & $95 \pm 11$ & $99 \pm 15$ & $91 \pm 10$ & $93 \pm 16$ & ns \\
\hline Cardiac index $\left(1 / \mathrm{min} / \mathrm{m}^{2}\right)$ & $2.8 \pm 0.7$ & $3.0 \pm 0.8$ & $2.4 \pm 0.4$ & $2.3 \pm 0.5$ & ns \\
\hline $\begin{array}{l}\text { Systolic pulmonary arterial } \\
\text { pressure }(\mathrm{mmHg})\end{array}$ & $26 \pm 7$ & $30 \pm 4$ & $39 \pm 16$ & $50 \pm 8^{* *}$ & $<0.002$ \\
\hline $\begin{array}{l}\text { Diastolic pulmonary arterial } \\
\text { pressure }(\mathrm{mmHg})\end{array}$ & $9 \pm 4$ & $12 \pm 3$ & $20 \pm 12$ & $27 \pm 7+† * *$ & $<0.001$ \\
\hline $\begin{array}{l}\text { Mean pulmonary arterial } \\
\text { pressure (mmHg) }\end{array}$ & $15 \pm 5$ & $18 \pm 3$ & $27 \pm 13$ & $35 \pm 7+† * *$ & $<0.001$ \\
\hline $\begin{array}{l}\text { Pulmonary capillary wedge } \\
\text { pressure }(\mathrm{mmHg})\end{array}$ & $9 \pm 5$ & $12 \pm 5$ & $17 \pm 9$ & $22 \pm 6++*$ & $<0.03$ \\
\hline Right atrial pressure (mmHg) & $5 \pm 2$ & $4 \pm 1$ & $10 \pm 9$ & $12 \pm 7$ & ns \\
\hline Stroke volume (ml/beat) & $77 \pm 7$ & $58 \pm 18$ & $46 \pm 14^{*}$ & $37 \pm 12^{* *}$ & $<0.002$ \\
\hline Stroke index $\left(\mathrm{ml} / \mathrm{beat} / \mathrm{m}^{2}\right)$ & $44 \pm 9$ & $38 \pm 11$ & $29 \pm 9$ & $26 \pm 11^{*}$ & $<0.02$ \\
\hline Stroke work $\left(\mathrm{ml}^{*} \mathrm{mmHg} /\right.$ beat $)$ & $6507 \pm 1287$ & $5154 \pm 2123$ & $3632 \pm 1305 *$ & $2760 \pm 755^{* *}$ & $<0.002$ \\
\hline $\begin{array}{l}\text { Stroke work index } \\
\left(\mathrm{ml}^{*} \mathrm{mmHg} / \text { beat } / \mathrm{m}^{2}\right)\end{array}$ & $3725 \pm 582$ & $3374 \pm 1327$ & $2257 \pm 829$ & $1902 \pm 615^{*}$ & $<0.008$ \\
\hline $\begin{array}{l}\text { Systemic vascular resistance } \\
\left(\text { dyne* } \mathrm{sec} / \mathrm{cm}^{5}\right)\end{array}$ & $1499 \pm 486$ & $1728 \pm 408$ & $1700 \pm 342$ & $2015 \pm 581$ & ns \\
\hline $\begin{array}{l}\text { Pulmonary vascular resistance } \\
\left.\text { (dyne* } \mathrm{sec} / \mathrm{cm}^{5}\right)\end{array}$ & $119 \pm 70$ & $108 \pm 48$ & $198 \pm 129$ & $324 \pm 196^{*}$ & $<0.02$ \\
\hline $\begin{array}{l}\text { Forearm blood flow } \\
(\mathrm{ml} / 100 \mathrm{ml} / \mathrm{min})\end{array}$ & $1.5 \pm 0.8$ & $1.8 \pm 1.3$ & $1.9 \pm 0.7$ & $0.8 \pm 0.4 \dagger$ & ns \\
\hline $\begin{array}{l}\text { Forearm vascular resistance } \\
(100 \mathrm{ml} * \mathrm{~min} / \mathrm{ml} / \mathrm{mmHg})\end{array}$ & $80 \pm 38$ & $84 \pm 56$ & $55 \pm 23$ & $129 \pm 57$ & ns \\
\hline $\begin{array}{l}\text { Venous stiffiness constant }(\mathrm{k}) \\
\quad(100 \mathrm{ml} / \mathrm{ml})\end{array}$ & $0.78 \pm 0.24$ & $1.00 \pm 0.48$ & $1.71 \pm 1.12$ & $2.32 \pm 1.19^{*}$ & $<0.02$ \\
\hline $\mathrm{r}$ & $0.98 \pm 0.02$ & $0.98 \pm 0.01$ & $0.98 \pm 0.01$ & $0.98 \pm 0.01 \uparrow$ & ns \\
\hline $\mathrm{V} 20(\mathrm{ml} / 100 \mathrm{ml})$ & $1.69 \pm 0.74$ & $1.40 \pm 0.68$ & $0.94 \pm 0.45$ & $0.59 \pm 0.20^{*}$ & $<0.03$ \\
\hline
\end{tabular}

V20 $=$ change of venous volume at a venous pressure of $20 \mathrm{mmHg} . \quad * \mathrm{p}<0.05, * * \mathrm{p}<0.01$ vs. Group $1 ;+\mathrm{p}<0.05$, †† $\mathrm{p}<0.01$ vs. Group 2 . 
Table III. Relation between Severity of Congestive Heart Failure and Plasma Concentration of Hormones

\begin{tabular}{l|cccc}
\hline & $\begin{array}{c}\text { Group } \\
(\mathrm{n}=6)\end{array}$ & $\begin{array}{c}\text { Group 2 } \\
(\mathrm{n}=4)\end{array}$ & $\begin{array}{c}\text { Group 3+Group 4 } \\
(\mathrm{n}=6)\end{array}$ & $\mathrm{p}$ \\
\hline Epinephrine $(\mathrm{pg} / \mathrm{ml})$ & $50 \pm 19$ & $72 \pm 86$ & $96 \pm 27$ & $\mathrm{~ns}$ \\
Norepinephrine $(\mathrm{pg} / \mathrm{ml})$ & $150 \pm 86$ & $318 \pm 180$ & $920 \pm 691^{*}$ & $\mathrm{p}<0.03$ \\
Angiotensin II $(\mathrm{pg} / \mathrm{ml})$ & $34 \pm 10$ & $(29 ; \mathrm{n}=1)$ & $(29,88 ; \mathrm{n}=2)$ &
\end{tabular}

* $\mathrm{p}<0.05$ vs. Group 1 .

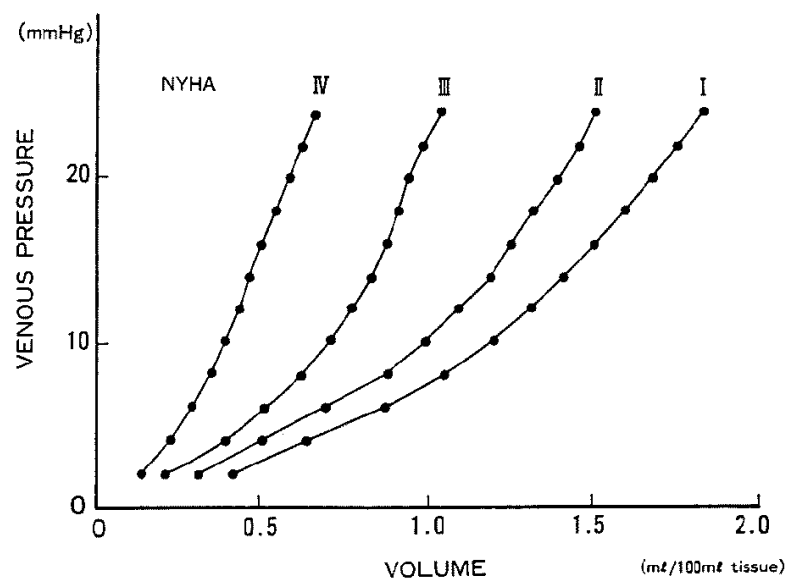

Fig. 2. The relationship between venous pressure-volume curves and New York Heart Association (NYHA) functional class. Venous pressure-volume curves were shifted to the left on the volume axis and became steeper according to the increase of functional class.

heart failure classified according to NYHA; systolic $(\mathrm{p}<0.002)$, diastolic $(\mathrm{p}<$ $0.001)$ and mean pulmonary arterial pressures $(p<0.001)$, pulmonary capillary wedge pressure $(\mathrm{p}<0.03)$, pulmonary vascular resistance $(\mathrm{p}<0.02)$, stroke volume $(p<0.002)$, stroke index $(p<0.02)$, stroke work $(p<0.002)$ and stroke work index $(\mathrm{p}<0.008)$. Plethysmographic studies revealed the relation between the severity of congestive heart failure and venous stiffness constant, $k$ $(\mathrm{p}<0.02)$, and between the severity and V20 $(\mathrm{p}<0.03)$.

Plasma concentration of norepinephrine was increased in congestive heart failure, and epinephrine had the same tendency (Table III). Angiotensin II was examined in 9 cases. A high plasma concentration of angiotensin II was observed only in 1 patient from Group 4.

Forearm venous pressure-volume curve and $\mathcal{N} Y H A$ classification:

Forearm venous pressure-volume curves in each group are presented in Fig. 2. The curves were shifted to the left on the volume axis and became 

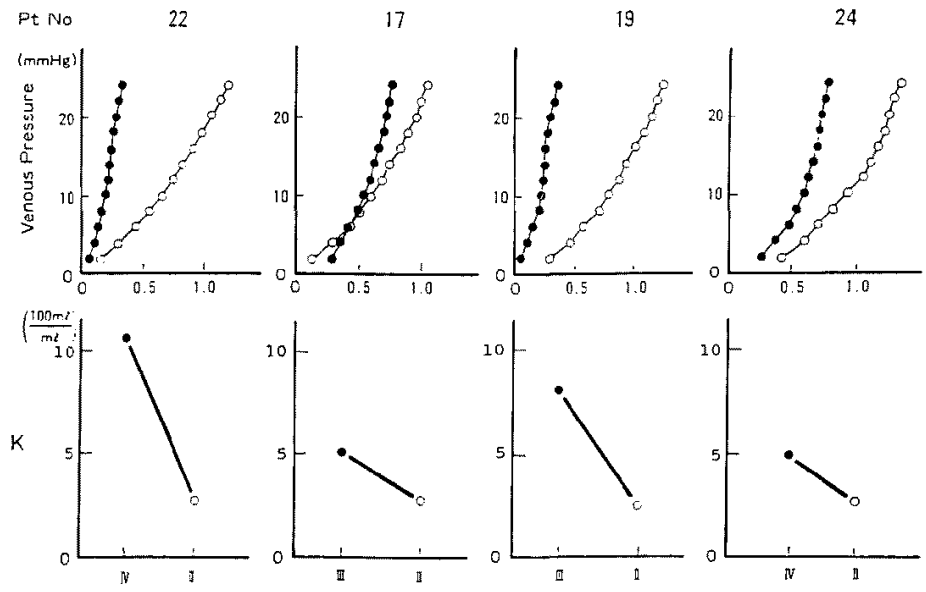

Fig. 3. The effect of treatment on venous distensibility in patients with severe congestive heart failure. Forearm venous pressure-volume curves were shifted to the right on the yolume axis and became less steep. Venous stiffness constant was reduced markedly after treatment of heart failure.

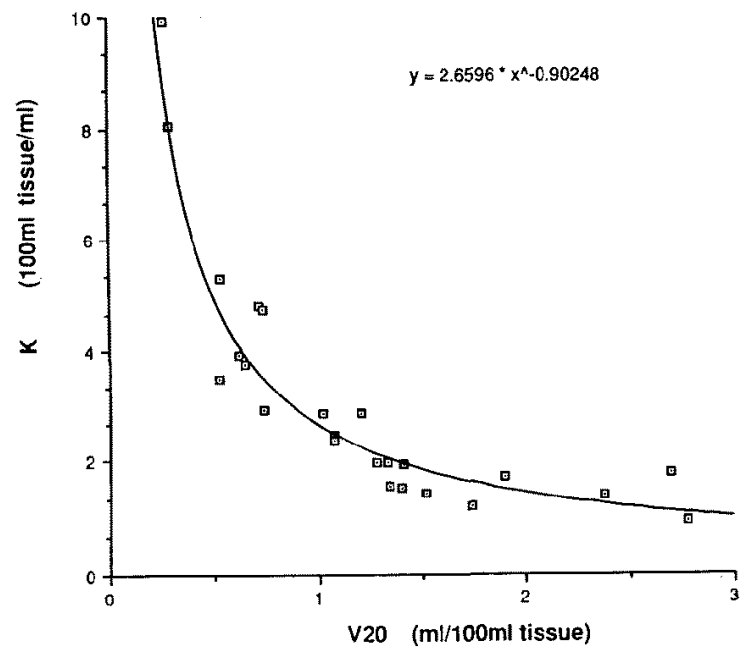

Fig. 4. Relationship between venous stiffness constant (k) and venous volume at a venous pressure of $20 \mathrm{mmHg}$ (V20). Venous stiffness constant was closely related to the venous compliance at a venous pressure of $20 \mathrm{mmHg}$. The relation was more prominent when the relation was analyzed with logarithmic V20 $(r=-0.90, p<0.001)$.

steeper as the NYHA functional class grade increased. That is, the degree of increase in venous tone was closely related to the severity of congestive heart failure.

Four patients underwent second plethysmographic studies after the re- 
Table IV. Relation between Venous Distensibility and Hemodynamic Parameters

\begin{tabular}{|c|c|c|c|c|c|}
\hline & \multicolumn{2}{|c|}{$\mathbf{k}$} & \multicolumn{2}{|c|}{$\mathrm{V} 20$} & \multirow{2}{*}{$\mathbf{n}$} \\
\hline & $\mathrm{r}$ & $\mathrm{p}$ & $\mathbf{r}$ & $\mathrm{p}$ & \\
\hline Heart rate & 0.55 & $<0.006$ & \multicolumn{2}{|c|}{ ns } & 24 \\
\hline Systolic pulmonary arterial pressure & 0.66 & $<0.001$ & -0.53 & $<0.008$ & 24 \\
\hline Diastolic pulmonary arterial pressure & 0.79 & $<0.001$ & -0.59 & $<0.003$ & 24 \\
\hline Mean pulmonary arterial pressure & 0.74 & $<0.001$ & -0.56 & $<0.004$ & 24 \\
\hline Pulmonary capillary wedge pressure & 0.54 & $<0.02$ & \multicolumn{2}{|c|}{$\mathrm{ns}$} & 24 \\
\hline Right atrial pressure & 0.51 & $<0.02$ & \multicolumn{2}{|c|}{ ns } & 24 \\
\hline Cardiac index & -0.45 & $<0.03$ & \multicolumn{2}{|c|}{ ns } & 24 \\
\hline Systemic vascular resistance & 0.45 & $<0.03$ & \multicolumn{2}{|c|}{ ns } & 24 \\
\hline Pulmonary vascular resistance & 0.73 & $<0.001$ & -0.59 & $<0.003$ & 24 \\
\hline Stroke index & -0.57 & $<0.004$ & 0.44 & $<0.03$ & 24 \\
\hline Stroke work index & -0.47 & $<0.02$ & 0.45 & $<0.03$ & 24 \\
\hline Norepinephrine & 0.64 & $<0.008$ & -0.52 & $<0.04$ & 16 \\
\hline Epinephrine & 0.56 & $<0.03$ & & & 16 \\
\hline Angiotensin II & \multicolumn{2}{|c|}{$\mathrm{ns}$} & \multicolumn{2}{|c|}{ ns } & 9 \\
\hline
\end{tabular}

gression of symptoms following treatment (NYHA IV->II, $\mathrm{n}=2$, Pt. Nos. 22, 24; NYHA III->II, n=2, Pt. Nos. 17, 19). The pressure-volume curve of the forearm veins and venous stiffness constant, $k$, demonstrated that stiffness of the forearm veins returned toward normal with improvement of symptoms (Fig. 3).

Venous stiffness constant and hemodynamic parameters:

There was a significant negative correlation between venous stiffness constant, $\mathrm{k}$, and venous compliance, V20, $(\mathrm{r}=-0.73, \mathrm{p}<0.001)$, and the logarithmic value of $\mathrm{V} 20$ was morc closely related to $\mathrm{k}(\mathrm{r}=-0.90, \mathrm{p}<0.001)$ (Fig. 4). Relationships between venous stiffness constant, k, and hemodynamic parameters are listed in Table IV in comparison with V20. Venous stiffness constant, $\mathrm{k}$, had significant correlations to pulmonary vascular resistance $(\mathrm{r}=0.73, \mathrm{p}<0.001)$ (Fig. 5), pulmonary arterial systolic $(\mathrm{r}=0.66, \mathrm{p}<$ $0.001)$, diastolic $(r=0.79, p<0.001)$, and mean $(r=0.74, p<0.001)$ pressures at simultaneous right heart catheterization (Fig. 6). Less significant correlations were found with systemic vascular resistance $(r=0.45, p<0.03)$ (Fig. 7), pulmonary capillary wedge pressure $(r=0.54, p<0.02)$, right atrial pressure $(\mathrm{r}=0.51, \mathrm{p}<0.02)$, cardiac index $(\mathrm{r}=-0.45, \mathrm{p}<0.03)$, stroke index $(\mathrm{r}=-$ $0.57, \mathrm{p}<0.004)$ and stroke work index $(\mathrm{r}=-0.47, \mathrm{p}<0.02)$. In contrast, V20 had no significant correlation to systemic vascular resistance, pulmonary capillary wedge pressure, right atrial pressure and cardiac index.

Hormonal analysis revealed a significant relationship between $\mathrm{k}$ and plasma norepinephrine concentration $(r=0.64, p<0.008)$. V20 also had less of 

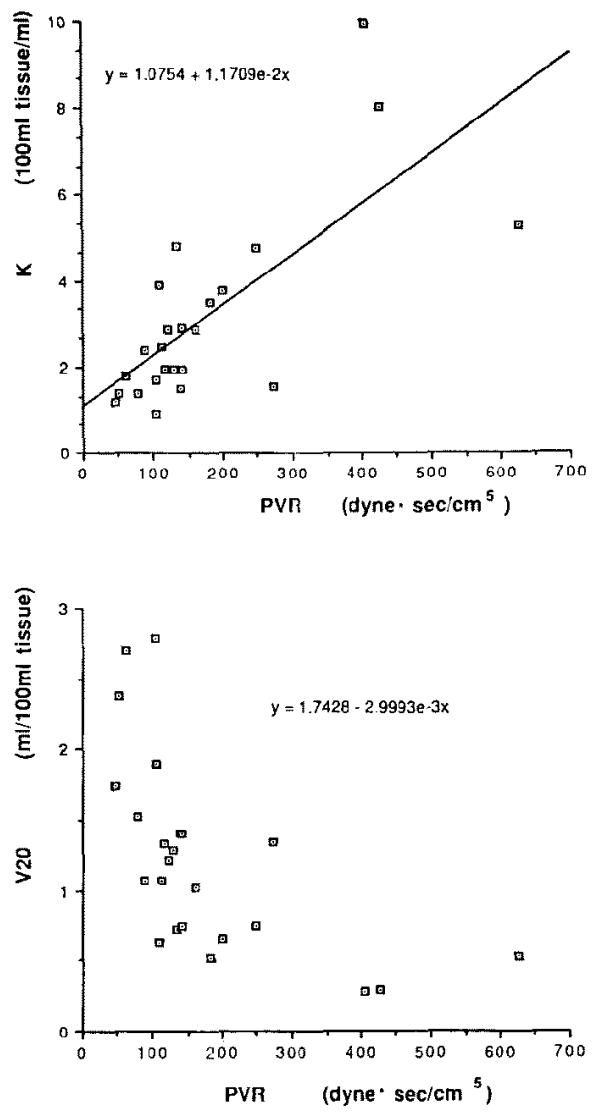

Fig. 5. Relationship between pulmonary vascular resistance (PVR) and parameters of venous distensibility. Significant relationships between pulmonary vascular resistance and both venous stiffness constant ( $k$ ) and venous compliance (V20) were observed.

a relation to norepinephrine $(r=-0.52, p<0.04)$. Plasma epinephrine concentration has a significant correlation to $\mathrm{k}(\mathrm{r}=0.56, \mathrm{p}<0.03)$ but not to V20. There was no relation between $\mathrm{k}$ or $\mathrm{V} 20$ and plasma angiotensin II concentrations.

\section{Discussion}

Venous distensibility and hemodynamic parameters in congestive heart failure:

Reduction of venous distensibility in patients with heart failure has been reported. ${ }^{2), 3)}$ Several mechanisms underlying the decreased venous distensibility have been proposed, including elcvated sympathetic nervous tone, in- 

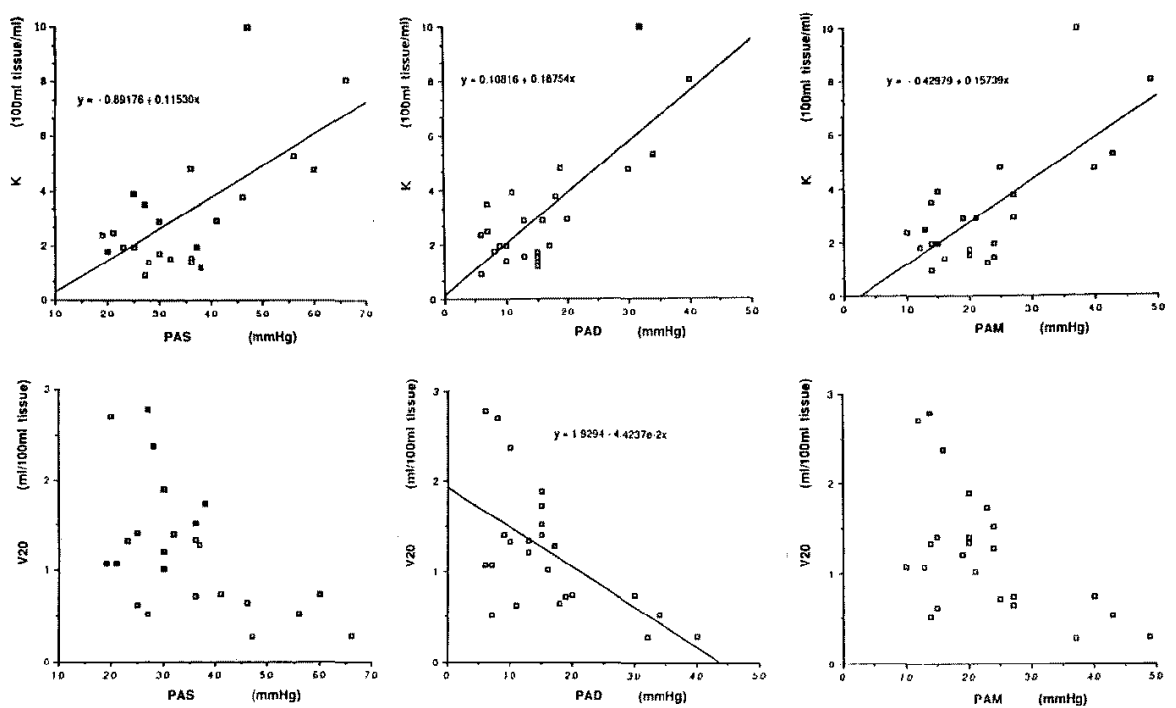

Fig. 6. Relationship between pulmonary arterial pressure and venous distensibility. Significant relationships between all systolic (PAS), diastolic (PAD) and mean (PAM) pulmonary arterial pressures and both venous stiffness constant ( $k$ ) and venous compliance (V20) were observed.

crease in circulating catecholamines and other vasoactive substances, local elements such as tissue pressure and interstitial edema and organic changes in the venous vessel wall. However, there has been no report clarifying the quantitative relation between venous distensibility and other hemodynamic parameters in patients with heart failure. In this study the venous stiffness constant, $k$, and the index of venous compliance at a venous pressure of $20 \mathrm{mmHg}$ (V20) were found to be closely related to the severity of congestive heart failure expressed by NYHA classification, hemodynamic parameters such as pulmonary arterial pressure and pulmonary vascular resistance. The relationship between these two parameters was not linear (Fig. 4) and k related to more hemodynamic parameters than V20. Venous stiffness constant, $k$, may be more sensitive to hemodynamic change than V20. In addition, venous parameters proved to be influenced by the plasma concentration of vasoactive hormone (norepinephrine). Girculating norepinephrine has been known to increase in congestive heart failure, the degree of increase being related to the severity of congestive heart failure. ${ }^{5)}$

Wc stopped medication at least 12 hours before the study. However, there is a possibility that the drugs affected venous distensibility. Isosorbide dinitrate (ISDN) decreases venous stiffness. In patients without heart failure venous stiffness was very low, ${ }^{3 \prime}$ and in this study ISDN was used mainly in 

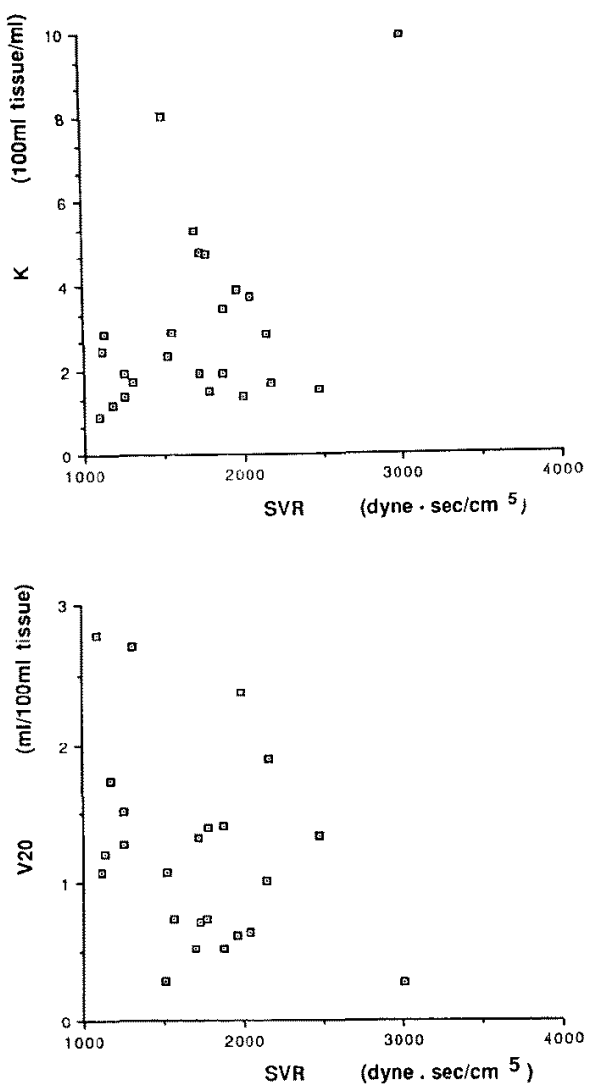

Fig. 7. Relationship between systemic vascular resistance (SVR) and parameters of venous distensibility. A weak relationship between yenous stiffness constant (k) and systemic vascular resistance was observed.

such patients (Table I). Digoxin increased venous stiffness in normal subjects but decreased venous stiffness in patients with congestive heart failure. ${ }^{12}$ ) Slow calcium channel blockade had no venodilating effect on venoconstriction evoked by norepinephrine infusion. ${ }^{14)}$ Furosemide may decrease venous stiffness by improving congestive heart failure. We believe that in this study these medications had no influence on the results.

\section{Plethysmography:}

Strain-gauge plethysmography using the acute occlusion technique is a useful method for evaluating peripheral circulation, especially in assessing venous distensibility. ${ }^{15,16)}$ Several other methods such as air or water-filled plethysmography, and an isotope labeled erythrocyte technique ${ }^{17}$ are utilized for the measurement of forearm volume changes. Water plethysmography directly measures forearm volume by enclosing the forearm in a water cham- 
ber. ${ }^{18), 19)}$ Theoretically, it is the only accurate method. Practically, however, it is rather difficult to obtain stable conditions with this method. Straingauge plethysmography measures forearm volume changes calculated from the changes in circumference measured by the electronic resistance of the stretched strain gauge. ${ }^{19)}$ Although this method is indirect in that it is based on an assumption, practically it is rather easy to obtain stable data. Forearm blood flow was calculated from the change in forearm volume during venous occlusion and is expressed in $\mathrm{ml}$ per $100 \mathrm{ml}$ tissue per minute. ${ }^{16)}$ A linear relationship between the values of forearm blood flow obtained with these two plethysmographic techniques is apparent, and the strain-gauge technique is regarded as a sufficiently reliable method for recording changes in limb volume. ${ }^{19)}$

Plethysmography is a noninvasive and simple technique to evaluate venous tone. However, it has several shortcomings. Room temperature affects the venous capacitance $\mathrm{e}^{201,21)}$ appreciably, so in our study the room tcmperature was kept constant during measurements. Secondly, the data obtained from the forearm do not necessarily represent the venous distensibility of the whole body. Thirdly, the compliance of individual veins may not be uniform even in the limb, and the time course of volume change for each vein may be different when pressure is applied. Capillary filtration and bone flow can influence the pressure-volume curve of veins. ${ }^{21}$ A previous study recommended that measurements should be made at an occlusion pressure of $60 \mathrm{mmHg}^{201}$ in order to exclude these disturbing elements as much as possible. But an application of $60 \mathrm{mmHg}$ may disturb the arterial flow of the forearm. Thus we used an occlusion pressure of $40 \mathrm{mmHg}$, which was used in a previous study. ${ }^{15)}$ With this pressure, arterial blood flow is considered to be affected far less.

Venous stiffness constant and venous compliance (V20, VV30):

In a previous study, ${ }^{8}$ venous distensibility failed to show significant relations to the severity of heart failure, previous drug therapy, venous pressure, plasma concentration of catecholamines or effect of phentolamine in patients with congestive heart failure. They used watcr plethysmography and assessed venous distensibility by venous volume at effective venous pressures of 15, 30 and $45 \mathrm{mmHg}$ with the occlusion method.

In other previous studies, venous compliance was evaluated by the pressure-volume curve or forearm volume at an effective venous pressure (a cuff pressure) of $30 \mathrm{mmHg}$ (VV30). ${ }^{22), 23)}$ The pressure volume curve itself gives a visual impression of compliance but is not appropriate for quantitative comparison. Forearm volume at an effective venous pressure of $30 \mathrm{mmHg}$ expresses a kind of venous compliance but it depicts only one point of the whole 
pressure-volume relation. The other method which Sharpey-Schafer ${ }^{24)}$ presented was the venous tone, forearm venous pressure-volume ratio. They made the assumption that both the forearm pressure curve and the volume curve were linear and used the pressure-volume ratio as a parameter of venous stiffness. In our study pressure-volume curves were not linear (Figs. 2 and 3), and venous tone was actually dependent on venous pressure, in other words venous tone changed at different venous pressures. Thus, we proposed a venous stiffness constant, $\mathrm{k}$, in order to quantify the distensibility of veins throughout the whole pressure-volume range. We fitted the pressure-volume relation to an exponential curve and obtained favorable results $(r=0.98 \pm 0.01$, $\mathrm{p}<0.01)$. This constant, we believe, expressed the pressure-volume relation of veins and their stiffiness very well compared to the venous compliance at a point of venous pressure (V20) (Table IV). The basal venous tone was found to be related to the degree of heart failure.

\section{Mechanism of venoconstriction in congestive heart failure:}

Zelis et $\mathrm{al}^{7)}$ reported that the increase in venous tone in patients with congestive heart failure was attributed mainly to interstitial factors such as tissue pressure or edema, because the effect of nitroglycerin was relatively small. But other reports suggest a mechanism related to sympathetic nerve effects on venous tone in patients with congestive heart failure by showing a return to normal tone following administration of phentolamine. ${ }^{8)}$ In our study venous distensibility returned almost to the normal range comparable with Group 1 during improvement of congestive heart failure (Fig. 3). In cases with prominent edema, interstitial factors may play a large part in the elevation of venous tone in congestive heart failure.

The available evidence suggests, at least in the dog, that the arteries and splanchnic veins contain mainly alpha $\mathbf{1}^{-}$, and the limb veins mainly alpha $2^{-}$ adrenergic receptors. ${ }^{25)-28}$ Others have reported that the vasoconstriction induced by exogenous norepinephrine was more effectively inhibited by the alpha $_{2}$-adrenoceptor blocker, yohimbine, whereas the vasoconstriction due to endogenously released norepinephrine was preferentially inhibited by the alpha $_{1}$-adrenoceptor blocker. ${ }^{29}$ ) Norepinephrine is thought to elicit contraction in human veins by acting on a mixed population of alpha $\mathbf{1}^{-}$and alpha $\mathrm{a}_{2}$-adrenoceptors. ${ }^{301}$ The non-selective alpha-blocking agent phentolamine caused a marked increase in the distensibility of the forearm veins in patients with congestive heart failure. ${ }^{8), 10)}$ The selective alpha $\mathrm{a}_{1}$-adrenergic blocker, prazosin, given to patients with congestive heart failure, acutely decreased vascular resistance in the limbs, splanchnic area and lungs, but not in the kidney; it evoked venodilatation in the limbs. ${ }^{17), 31)-33)}$

In patients with severe heart failure angiotensin II may contribute to the 
decrease in venous distensibility. The direct effects of angiotensin II on vascular smooth muscle cells are obvious in precapillary vessels, but relatively weak in the systemic veins. ${ }^{25}$ ) Besides directly affecting vascular smooth muscle cells, angiotensin II not only enhances their responsiveness to norepinephrine but also increases the amount of adrenergic transmitter made available to them. The responsiveness of the vascular smooth muscle cells to norepinephrine and angiotensin II can be amplified by 5-hydroxytryptamine (5-HT), which is released from aggregating platelets. ${ }^{34)}$ Venoconstriction by 5 -HT was mediated predominantly by 5 -HT receptors. ${ }^{30}$ Conversely, a number of neurohumoral mediators (acetylcholine, bradykinin, ATP, thrombin, arachidonic acid) cause the endothelial cells to generate inhibitory signals for the smooth muscle cells of the media. ${ }^{35), 36)}$

In an experiment with rabbits, the tolerance of veins to nitrates was less than that of arteries and indomethacin was able to evoke nitrate-tolerance in arteries but not in veins. ${ }^{37}$ ) These results suggest that the prostaglandin system appears to be involved only in arteries.

Limitation of the study:

The most serious problem of plethysmography is that measurement can be done only in limbs. In dogs the distribution of alpha-adrenoceptors is reported to differ between cutaneous and splanchnic veins. ${ }^{27)-30}$ In humans splanchnic veins may have different characteristics from forearm veins, but at present we have no means to substantiate or to measure these differences.

Clinical implications:

Venous distensibility was quantified by the venous stiffness constant, $k$, which turned out to be clearly related to the severity of clinical symptoms, pulmonary congestion, pumping function of the heart and plasma concentration of norepinephrine. The venous stiffness constant may play an important role in understanding and evaluating congestive heart failure and be useful in evaluating the effects of drugs on forearm veins.

\section{ACKNOWLEDGMents}

We appreciate the thoughtful review of the manuscript by Dr. Jay N. Cohn of the University of Minnesota Medical School. We express our gratitude to the house staff and attending physicians from the Second Department of Internal Medicine at Tokyo University for their assistance.

\section{REFERENCES}

1. Guyton AC, Jones CE, Coleman JG: Circulatory Physiology: Cardiac Output and Its Regulation, WB Saunders, Philadelphia, p 237, 1973

2. Abboud FM, Heistad DD, Mark AL, Schmid PG: Reflex control of the peripheral circula- 
tion. Progr Cardiovasc Dis 18: 371, 1976

3. Zelis R, Nellis SH, Longhurst J, Lee G, Mason DT: Abnormalities in the regional circulations accompanying congestive heart failure. Progr Cardiovasc Dis 18: 181, 1975

4. Curtiss C, Cohn JN, Vrobel T, Franciosa JA: Role of the renin-angiotensin system in the systcmic vasoconstriction of chronic congestive heart failure. Circulation 58:763, 1978

5. Thomas JA, Marks BH: Plasma norepinephrine in congestive heart failure. Am J Cardiol $41: 233,1978$

6. Cohn JN, Franciosa JA: Vasodilator therapy of cardiac failure. N Engl J Med 297: 27, 1977

7. Zelis R, Flaim SF: Alterations in vasomotor tone in congestive heart failure. Progr Cardiovasc Dis 24: 437, 1982

8. Villani F, Perret G, Jequier E, Schelling JL: Effects of phentolamine on peripheral venous distensibility in congestive heart failure. Eur J Glin Pharmacol 7: 11, 1974

9. Vanhoutte PM: Adjustment in the peripheral circulation in chronic heart failure. Eur Heart J 4 (suppl A): 67, 1983

10. Zelis R: The contribution of local factors to the elevated venous tone of congestive heart failure. J Clin Invest $54: 219,1974$

11. Wood JE, Litter J, Wilkins RW: Pcripheral vcnoconstriction in human congestive heart failure. Circulation 13: 524,1956

12. Mason DT, Braunwald E, Karsh RB, Bullock FA: Studies on digitalis. X. Effects of ouabain on forearm vascular resistance and venous tone in normal subjects and in patients in heart failure. J Glin Invest 43: 532, 1964

13. The Criteria Committee of the New York Heart Association: Diseases of the Heart and Blood Vessel: Nomenclature and Criteria for Diagnosis, 6th Ed, Little Brown, Boston, 1964

14. Robinson BF, Dobbs RJ, Kelsey CR: Fffects of nifedipine on resistance vessels, arteries and veins in man. Br J Clin Pharmacol 10: 433, 1989

15. Esquivel M, Burns RJ, Ogilvie RI: Cardiovascular effects of enprofylline and theophylline. Glin Pharmacol Ther 39 : 395, 1986

16. Mason DT, Braunwald E: The effects of nitroglycerin and amyl-nitrite on arteriolar and venous tone in the human forearm. Circulation 32: 755, 1965

17. Wood JE, Eckstein JW: A tandem plethysmograph for study of acute responses. J Clin Invest 37: 41, 1985

18. Lindblad LE: Non-invasive techniques used to monitor peripheral circulatory changes induced by nitroglycerin. Acta Pharmacol Toxicol 59 (suppl VI): 109, 1986

19. Whitney RJ: The measurement of volume changes in human limbs. J Physiol 121: 1, 1953

20. Sundberg S, Gastren M: Drug- and temperature-induced changes in peripheral circulation measured by laser-Doppler flowmetry and digital-pulse plethysmography. Scand J Clin Lab Invest 46: 359,1986

21. Colardyn F, Hansen M, Glement DL: Values of venous occlusion plethysmography to study venoactive medication in men. Inter Angio 4: 215, 1985

22. Zelis R, Capone R, Mansour E, Field JM: The effects of short-term venous congestion on forearm venous volume and reactive hyperemia blood flow in human subjects. Circulation 57: 1001,1977

23. Zelis R, Mason DT: Isosorbide dinitrate: Effect on the vasodilator response to nitroglycerin. J Am Med Ass 234: 166, 1975

24. Sharpey-Schafer EP: Venous tone. Br Med J 2: 1589, 1961

25. Shepherd JT, Vanhoutte PM: Veins and Their Control, WB Saunders, London, 1975

26. Shepherd JT, Vanhoutte PM: The Human Cardiovascular System: Facts and Concepts. Raven Press, New York, 1979

27. Vanhoutte PM, Verbeuren $\mathrm{TJ}$, Webb RC: Local modulation of adrenergic neuroeffector interaction in the blood vessel wall. Physiol Rev 61: 151, 1981

28. Vanhoutte PM: Heterogeneity of postjunctional vascular alpha-adrenoceptors and handling of calcium. J Cardiovasc Pharmacol 4: S91, 1982 
29. Brummelen P, Jie K: Heterogeneity of vascular alpha-adrenoceptors in man. Can J Physiol Pharmacol 65: 1644, 1987

30. Arner M, Hogestaett ED: Contractile effects of noradrenaline and 5-hydroxytryptamine in human hand veins: A pharmacological receptor characterization. Acta Physiol Scand 128: 209,1986

31. Awan NA, Miller RR, Maxwell K, Mason DT: Effects of prazosin on forearm resistance and capacitance vessels. Clin Pharmacol Ther 22: 79, 1977

32. Miller RR, Awan NA, Maxwell KS, Mason DT: Sustaincd reduction of cardiac impedance and preload in congestive heart failure with the antihypertensive vasodilator prazosin. N FnglJ Med 297: 303, 1977

33. Colucci WS, Holman BL, Wynne J, Carabello B, Malacoff R, Grossman W, Braunwald E: Improved right ventricular function and reduced pulmonary vascular resistance during prazosin therapy of congestive heart failure. Am J Med 71: 75, 1981

34. Vanhoutte PM: Does 5-hydroxytryptamine play a role in hypertension? Tr Pharmacol Sci 3: 370, 1982

35. Furchgott RF: The requirement for endothelial cells in the relaxation of arteries by acetylcholine and some other vasodilators. Tr Pharmacol Sci 2: 173, 1981

36. Vanhoutte PM, DeMey J: Control of vascular smooth muscle function by the endothelial cells. Gen Parmacol 114: 39, 1983

37. Rosen R, Koeing E, Klaus W: Different sensitivities of arteries and veins to glyceryltrinitrateinduced relaxation and tolerance: An "in vitro" study on isolated vessels from rabbits. Arch Int Pharmacodyn 285: 226, 1987 